\title{
Lettuce quality in greenhouse with different technological levels
}

\author{
Vitor Gonçalves da Silva*, Thais Queiroz Zorzeto Cesar.
}

\begin{abstract}
Technologies for protected lettuce (Lactuca sativa) crop have been gaining ground in scientific studies, in search of alternatives which increases productivity, quality and loss reduction in the production of the most consumed leafy vegetable in Brazil. Greenhouses provides to crops controlled conditions of temperature and relative humidity, to held within the optimal ranges for plant development and ensuring thermal comfort. This research work assesses the influence of greenhouses with different technology levels (natural ventilation, red shade net and evaporative cooling system) on lettuce grown and quality attributes. The study was held at FEAGRI/UNICAMP, conducting a 45-days growth cycle of green and ruby 'mimosa' lettuce seedlings in pots with pine bark substrate drip-irrigated with nutrient solution. At the end of the cycle, plants were assessed in terms of their physical and physico-chemicals atributtes and chlorophyll and anthocyanin contents. Red shade net intensifies red spectral band and promotes high rates of vegetative and radicular growth. Leafy vegetable growing in greenhouses with shade net enhances bioactive compounds and pigments synthesis, in addition to thermal comfort conditions, increases anthocyanins content. Better quality atributtes are achieved in thermal comfort provided by using evaporative cooling system for vegetable crop in greenhouses.
\end{abstract}

Key words:

Anthocyanin, evaporative cooling, red shade net.

\section{Introduction}

A strong imbalance between population growth and world food demand has been required to reduce food losses and wastage. Protected crop promotes benefits, increasing productivity, availability and quality in food growing in greenhouses, providing to crops controlled conditions of temperature and relative humidity, to held within the optimal ranges for plant development and ensuring thermal comfort. However, cooling is essential to achieve these conditions in tropical and subtropical regions, especially in the summer, although the most part of greenhouses in Brazil are still at low technological and climate control levels. This research work assesses the influence of greenhouses $(\mathrm{GH})$ with different technology levels (natural ventilation $(\mathrm{GH} 1)$, red shade net $(\mathrm{GH} 2)$ and evaporative cooling system (GH3)) on lettuce (Lactuca sativa) grown and quality attributes, conducting a 45-days growth cycle of green and ruby 'mimosa' lettuce seedlings in pots with pine bark substrate drip-irrigated with nutrient solution. At the end of the cycle, plants were assessed in terms of their fresh and dry mass, plant length, number of leaves, moisture content, $\mathrm{pH}$, soluble solids, total titratable acidity, color parameters and chlorophyll and anthocyanin contents.

\section{Results and Discussion}

High PAR (Photosynthetically Active Radiation) values were noticed at $12 \mathrm{pm}$ in $\mathrm{GH} 1, \mathrm{GH} 3$ and $\mathrm{GH} 2$, in decreasing order, as shown in Image 1.

Image 1. PAR over time in greenhouses and outside.
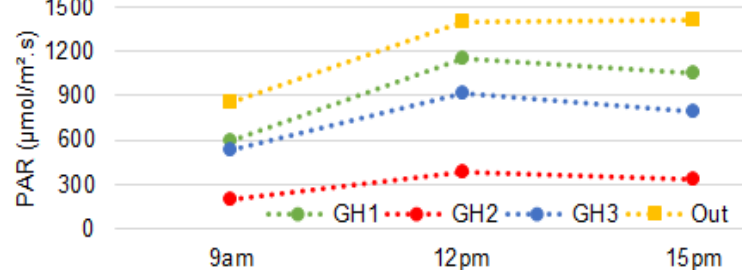

There was a $28 \%$ drop of PAR by 5 -years use plastic cover (GH3) compared to new plastic cover (GH1). By comparing $\mathrm{GH} 1$ to $\mathrm{GH} 2$, PAR decreased $68 \%$ due red shade net in $\mathrm{GH} 2$.
Chart 1. Average temperature (Tair) and relative humidity (RUair) of the air over time in greenhouses.

\begin{tabular}{ccccccc}
\hline \multirow{2}{*}{ Time } & \multicolumn{3}{c}{ Tair $\left({ }^{\circ} \mathrm{C}\right)$} & \multicolumn{4}{c}{ RUair (\%) } \\
& GH1 & GH2 & GH3 & GH1 & GH2 & GH3 \\
\hline 9am & 29 & 29 & 15 & 65 & 63 & 79 \\
$12 \mathrm{pm}$ & 37 & 38 & 31 & 45 & 42 & 62 \\
$15 \mathrm{pm}$ & 41 & 40 & 33 & 35 & 37 & 58 \\
\hline
\end{tabular}

$\mathrm{T}$ averages were higher in $\mathrm{GH} 1$ than $\mathrm{GH} 2$ and $\mathrm{GH} 3$, respectively, due natural ventilation $(\mathrm{GH} 1, \mathrm{GH} 2)$ versus evaporative cooling (GH3), while $\mathrm{RU}$ were inversely proportional. Lettuce in $\mathrm{GH} 2$ presented the highest mass (106.7g green; $82.4 \mathrm{~g}$ ruby) and length $(26.0 \mathrm{~cm}$ green; $25.1 \mathrm{~cm}$ ruby) due red spectral band intensification by red shade net, which stimulates vegetative growth. Anthocyanin content was higher in ruby lettuces than in green ones, since this pigment is responsible for ruby color. The highest anthocyanin content was achieved in $\mathrm{GH} 3$ ruby lettuces $\left(1.15 \mathrm{mg} .100 \mathrm{~g}^{-1}\right)$, since them are increased under thermal comfort and good quality and quantity of incident radiation. There were no substantial differences in chlorophyll content and physico-chemical attributes for different environments and lettuce varieties.

\section{Conclusions}

Longer usage time of plastic cover entails transmissivity decrease of solar radiation in greenhouse. Red shade net intensifies red spectral band and improves vegetative growth. Leafy vegetable growing in greenhouses with shade net enhances bioactive compounds and pigments synthesis, in addition to thermal comfort conditions, increases anthocyanin content. Lettuce quality attributes are influenced by $\mathrm{T}$ and UR and better results are achieved in thermal comfort conditions provided by using evaporative cooling system for vegetable crop in greenhouses.

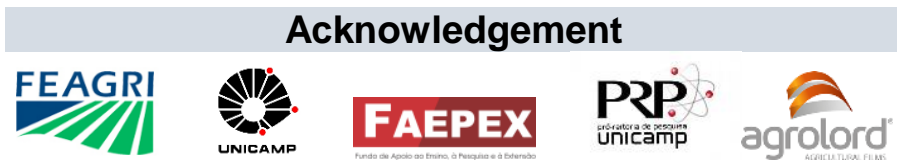

